\title{
"Laf wan kill me die" (I almost died laughing): An analysis of Akpos jokes and the readers' responses
}

\author{
Ibukun Filani \\ McPherson University, Ogun State, Nigeria \\ Phylani@yahoo.com
}

\begin{abstract}
Studies on humour have acknowledged that responses to jokes are important aspects of a joking exchange; however, investigation of joke recipients' responses has received little attention from humour scholars. Moreover, the linguistic investigations of jokes have been limited to native speakers' contexts, leaving ESL contexts out. Therefore, this study examines readers' responses to a genre of jokes in Nigerian online spheres, Akpos jokes, with a view to characterising their forms and functions. Akpos jokes are humorous narratives created around an imaginary character called Akpos. Jokes are randomly collected from a blog and readers' responses were derived from a Facebook page in which Akpos jokes are published. Using computer paralanguage and language mixing in writing the jokes and the responses, the jokes and the reactions to them mirror the online and the Nigerian ESL contexts in which they are situated. Readers use their responses to indicate affiliation, disaffiliation with the joke, or to introduce something that has nothing to do with the subject of the joke or humour. Readers also use their responses to argue for and/or against the humorousness the jokes.
\end{abstract}

Keywords: Akpos jokes, ESL, humour, computer paralanguage, responses/reactions to joke.

\section{Introduction}

Studies on the conversational use of jokes and humour have focused on the structure of jokes, joke types and sequential organisation of jokes in conversations (Sacks 1974; Attardo 1994; Norrick 2000; Dynel 2009). Other linguistic studies on humour, for instance Yus (2003) and Krikmann (2006), have focused on the mechanisms of humour and the pragmatics of joke interpretation. As observed by Adetunji (2013), several of these studies on humour have been limited to native speakers' context, leaving out joking in contexts where English functions as a second language (ESL). Joke recipients' responses, especially from ESL contexts, have not been explored in humour research. This study, therefore, seeks to analyse joke recipients' responses in order to explore their forms and functions. Specifically, the study presents an analysis of readers' responses to internet mediated humour in the Nigerian ESL context. Internet mediated humour is defined, here, as humour presented through the means of internet platforms such as Facebook, chatrooms, YouTube, blogs, and websites where jokes are 
published. For the purposes of analysis, the study focuses on a genre of Nigerian jokes, the Akpos jokes, which are very popular in Nigerian social media space.

This paper is divided into six sections. The first is the introduction to the study. Section two discusses the methodology of data collection. The description of the data, Akpos jokes, begins in section three while the analysis of reactions to the jokes commences in section four. The analysis is divided into two parts. The first part presents the forms of the readers' responses, while the second one presents the functions of these responses. In section five, the findings of the study are further discussed, while section six provides the conclusion of the study.

\section{Methodology}

For the purpose of this study, jokes were randomly collected from a joke blog, while readers' responses were derived from the Facebook platform, Akpos the comedian. There are several Facebook pages where Akpos jokes are published, but Akpos the comedian was selected because it enjoys large followership (at the time of data collection, in January 2015, the page has the highest number of likes, 710873). In addition, because it is a Facebook fan page, the jokes are made easily accessible to people. Unlike Facebook pages that demand friendship requests to be sent, the discourse on this page is not predicated on developing or continuing friendships. In technical terms, there is no previous or ongoing interpersonal relationship between the producer(s) of the jokes and the readers. Akpos jokes and their responses do not result from internet "cooperative conversational humour" (Knight 2008: 482), as any Facebook user could find the jokes, read them, and then comment on them.

Akpos joke pages on Facebook as well as blogs provide instances of publicly available chat rooms. A publicly available chat room is non-institutionalised. It is one in which "participants communicate primarily for recreational purposes" and it is different from "institutionalised chats" (Vandergriff 2010: 242):

Examples of differences between public chat rooms and institutionalised ones include the organisation of the chat by the teacher or moderator, joint tasks or goals, previously determined themes, fluctuation and number of participants, and familiarity of participants.

(Vandergriff 2010: 242)

In public joking genres, the number and demographic features of the recipients cannot be determined. Several people can join, like, or comment on the page without any form of restriction. In several social media pages, there is usually an administrator who would take down disrespectful and offensive comments. However, in Akpos the comedian, it seems that the administrator does not censor the comments as there are several comments on the jokes that are vulgar and abusive. Responses were taken only from the Facebook page, because readers did not comment by posting their written reactions to the jokes on the blogs even though there was an option for it. This may be due to the differences in the nature of Facebook and the blog. In Facebook, once a user likes a page, posts on the page will appear on the Facebook user's page. Moreover, commenting on Facebook page demands a single action, while commenting on blogs demands more actions in the sense that readers have to include their names as well as their reactions. 


\section{Akpos jokes}

Akpos jokes are innovative humorous narrations found in internet platforms in Nigeria. Communicative platforms on the internet provide Nigerians new opportunities for displaying creativity and cultural spaces for articulating their ideological inclinations. The platforms also accommodate the mode for joking, which Dynel (2009: 1286) calls "humorous mode/frame/key". In the humorous mode, speakers need not sincerely mean what their humorous utterances convey. It is this frame of communication that licences the production of Akpos Jokes. Akpos jokes are so named because they are created around an imaginary character Akpos, who is always the major character in the jokes and sometimes the butt of the jokes. There is no (comic) image, picture, or drawing that could be exclusively assigned to Akpos. Rather, the image of Akpos is reinforced by the utterances and actions adduced to him in the narratives.

Ayakoroma (2013) describes Akpos jokes as a genre of humour in Nigerian social media space. According to him, the jokes centre on the life of a clever boy called Akpos, who is presumably a teenager and whose character is predictable. In the jokes, Akpos' responses constitute the humorous peaks of narratives. With his responses, Akpos is depicted as a oneway thinker, who always looks for the easiest way to solve problems, and who, as a trickster, sometimes manipulates other characters to his own advantage.

Akpos jokes could be viewed as a reflection of the sociocultural realities in Nigeria. The name Akpos is clipped from some common names in the Niger-Delta region of Nigeria. Some of these names are Akporido, Akpofure, Onoakporobo, and Akpororo. The Nigeria Niger-Delta region is known for its youthful restiveness because the inhabitants no longer have their normal means of livelihood, that is, fishing. With the exploration of crude oil, fishing activities in the area became paralysed. Rather than providing basic amenities for the indigenes, the government and the oil companies working in the area have chosen to neglect the region over the years. This led to the restiveness of the occupants, especially the youths. Furthermore, Akpos is the real name of the progenitor of Nigerian stand-up comedy, whose stage name is Ali Baba. Ali Baba's real name is Atunyota Alleluia Akporobomerere (Gabriel 2012). From the foregoing, it can be suggested that the use of Akpos as the major character in these jokes is a reflection of the socio-cultural realities in Nigeria. I view the character Akpos as the online version of a common character in Nigerian stand-up routines, that is, Warri Boy. Warri is a major city in Nigerian Niger-Delta region. Warri Boy is a common target which Nigerian comedians use in two ways: to refer to themselves (especially comedians such as Ali Baba and I Go Dye who originate in the Niger-Delta region) and to satirise militant inclinations in the indigenes of the Niger-Delta region.

\subsection{Presuppositions underlying the Akpos jokes}

According to Delogu (2009: 195), presuppositions "are propositions whose truth is taken for granted during a communicative interaction". In pragmatics, presuppositions are viewed as background beliefs which make up the common ground between participants in a communication exchange. The use of humour in conversation largely depends on the presuppositions that exist between participants. Joke recipients find a joke amusing only if they are able to identify what the joke teller has taken for granted. In noting the value of presuppositions in humorous exchanges, Holmes \& Marra (2002) opine that many instances of humour require shared knowledge for an addressee to understand and appreciate them. Similarly, Galiñanes (2000: 101) notes that "humorous discourse [...] is based on the assumption of presuppositions, moral, social, cultural and even generic", which are shared by 
the joke tellers and their recipients. Such presuppositions are manipulated by the joke tellers and are readily available to the recipients (Galiñanes 2000).

A speaker can only say a joke when s/he is aware that the addressees are aware of the underlying background assumptions that are needed for the interpretation of the joke. These background assumptions include the belief that the addressees will not take the joke at face value, and the belief that the situation of interaction permits her/him to tell a joke. Although there may not be any form of ongoing interpersonal relationship between the producer of Akpos jokes and their readers, there are presuppositions which guide the producer(s) of the texts. The recipients of Akpos jokes must also be aware of these presuppositions in order to rightly interpret the joke text.

In unmediated conversational joking, joke tellers could use several cues to inform recipients that they are about to tell a joke (Attardo 1994). These cues cannot be used in the "telling" of Akpos jokes since the joke texts are written in an online platform that is devoid of the affordances of face-to-face communication. This is where presuppositions come in. The presuppositions are assumptions which the joke writers know will aid the readers in comprehending the texts.

In Akpos jokes, the presuppositions are informed by the sociocultural context in which the jokes are situated. Primarily, they include assumptions that border on language, culture, the situations presented in the joke, and the Nigerian context in general. Thus, in uncovering the presuppositions, attention is paid to the form of language used in presenting the jokes, the meaning potentials of the joke texts, and the situation which the joke refers to. As much as the joke writers are guided by these background beliefs while constructing the jokes, the recipients' responses are also motivated by them.

\subsubsection{The stereotyping of an imaginary character}

In Akpos narratives, it is assumed that the character Akpos exists. The character is embedded in two stereotypical images. The first image presents Akpos as a stupid individual whose intelligent quotient is too low for his age. Other characters in the narratives presume that Akpos should be capable of logical thinking, even though Akpos utterances and actions depict otherwise. His actions always indicate stupidity. The stupid script attached to Akpos by the producers of the jokes can be explained by using two perspectives. In the first, when it is considered within the purview of superiority approach to humour (Attardo 1994), Akpos will be seen as having a defect which functions as the stimulus for laughter. By assigning the negative feature of stupidity to Akpos, the writers of Akpos arouse mocking laughter and a feeling of pleasure at the character's presumed inability and inferiority (Ermida 2009). Secondly, drawing on Davies' (1990) theory of ethnic jokes which shows that the targets of jokes are close to the joke teller, it can be argued that the stupidity script is attached to Akpos because the character is viewed as a representation of a minority ethnic group in the NigerDelta region of Nigeria. ${ }^{1}$ Davies (1990) suggests that ethnic humour demands that the target should be close to the joke teller. Ethnic humour, therefore, measures how the target is construed. The stupidity script of Akpos is not unconnected to how the Niger-Deltans are perceived by dominant groups in Nigeria - as lazy, restless, unserious, and always finding the easiest route to wealth. This cognitive context sets up the jokes and other anecdotes in which Akpos is ridiculed.

The stupid script attached to Akpos is sometimes contradicted when he is presented as a trickster who gets himself into trouble and finds a way out at the expense of other characters in the jokes. The use of a trickster in the jokes is not entirely new in Nigerian lore traditions. For instance, in Yoruba folktales, the tortoise is presented as a small individual who schemes against other individuals and takes advantage of them. The tortoise creates chaos which only 
he can solve, and sometimes in the process gets himself into trouble. Like the tortoise, Akpos sometimes gets himself into trouble when he carries out his pranks. When he gets into trouble, he uses his tricks to scheme others into the trouble he has created while he exonerates himself unscrupulously. Akpos jokes differ from jokes which are part of the traditional folklore in Nigeria. Unlike those traditional folktales which are conveyed in native/first languages in the country, Akpos jokes are primarily conveyed in English - the country's lingua franca. Example 1 illustrates Akpos as a trickster:

\section{Example 1}

Background: Akpos, as a houseboy, usually sneaks into his Oga's room and helps himself with whatever he can find. One day his Oga bought Pastis, a wine which changes colour whenever water is added to it. Akpos was unaware of this, and when he sneaked into the room again he drank some of the wine and added water to fill up the bottle. Immediately, the wine changed colour and Akpos knew he was in deep trouble. Not knowing what to do, Akpos ran into the kitchen. Meanwhile his Oga and Madam were seated in the parlour. When his Oga realised that his Pastis had been touched, he decided to question Akpos:

Oga: Akpos

Akpos: Oga

Oga: Who drank my pastis?

(No answer)

Oga: Akpos, Who drank my pastis?

(No answer. Oga went to the kitchen to look for Akpos and found him)

Oga: Are you insane or what? Why when I called, you replied me by saying

'Oga' but when I asked you a question you didn't answer me.

Akpos: Oga, when you are in the kitchen you don't understand anything except your name.

Oga: Is that so? Okay go to the parlour, stand beside Madam and ask me a question while I stand here.

(Akpos went and did what Oga said)

Akpos: Ogaaaa

Oga: Yes Akpos

Akpos: Who goes into the maid's bedroom when madam is not at home?

(No answer)

Akpos: Ogaaaaaaa!!! You dey hear me, I say who dey sneak enter the house

girl room when madam no dey house. [Translation: Oga, you can hear me. I am asking you, who sneaks into the house girl's room when Madam is not at home.]

(No answer. Oga runs out of the kitchen)

Oga: Wonders shall never end. Akpos, it is true $\mathrm{o}^{2}$, when one is in the kitchen, one does not hear anything except one's name.

Madam: That's not true. It's a lie.

Akpos: Madam, do you want to be tested?

Madam: Yes

Akpos: Oya enter the kitchen [Trans: Ok, enter the kitchen]

(She enters the kitchen).

Akpos: Madam!

Madam: Yes Akpos

Akpos: Who is junior biological father? Me or Oga?

(Madam rushed out of the kitchen) 
Madam: This kitchen needs to be fumigated o

An important aspect of the humour in Example 1 is the role played by Akpos, involving how he cunningly diverted the attention of his boss (Oga) from finding out who drank the wine, to "understanding nothing but only one's name while in the kitchen". Akpos' trick is also targeted at his boss' wife (Madam). The prank played by Akpos in the joke is to expose supposed secrets of his Oga and Madam (the couple's infidelity to each other), when his Oga was attempting to uncover Akpos secret acts (stealing his master's wine). Another factor that contributes to humour in the joke is the surprises that come with the roles played by the characters in the joke and the propositions of Akpos, especially those that reveal the secrets of his master. The roles played by Akpos, Oga, and Madam bring up surprises by contradicting expectations, in that it is quite abnormal in the Nigerian context for a houseboy to dictate the decision of his master. In Nigeria, house servants are not allowed to call the shot in the homes where they serve. They are not meant to give suggestions to their bosses (Oga and Madam) and they cannot question the actions of their bosses. They are meant to be seen and not heard. However, in Example 1 we find Akpos suggesting that his Madam be "tested" and questioning both his Oga and Madam.

The trickster script attached to Akpos can also be explained using Davies' (1990) thesis of ethnic humour. The trickster script is related to the canny script suggested by him. A group is targeted as canny if it takes an activity too seriously or if it is too calculative. In addition, a canny script is attached to a group if the group is considered unreliable and strange. Whenever Akpos is presented as a trickster, he is endowed with weird and uncanny behaviour and actions. Such representation of the character shows that he is unreliable and incompatible with the sociocultural norms of the context he originates in.

\subsubsection{The expectation of humour}

As the word joke conjures expectations of funniness, so does the name Akpos: it bears an expectation of amusement or funny behaviour. This is not unconnected to the kinds of stereotypes attached to Akpos. In conversations, Akpos is often used as a label and an abusive term for someone who acts stupidly or makes a remark that is not related to the communicative context. As earlier mentioned, Akpos is the real name of the progenitor of the Nigerian stand-up comic; also, another stand-up comedian adopts Akpos as his stage name. In the jokes and outside the world of the jokes, therefore, the name Akpos is associated with humour in Nigeria. The role assigned to Akpos is a replica of the roles and functions of fools in literary text, especially the Shakespearean fool tradition. Shakespearean fool is also adopted in indigenous Nigerian literary genres (see Adeleke 2007). Besides, Akpos is a form of what Goriunova (2012) terms new media idiocy, but which is performed in Nigerian social media space. Akpos jokes, as Goriunova (2012) observes, are embedded with aspects of humour: laughter, the comic, satire, and parody. The character of Akpos is comic and parodic in the Bergsonian sense.

\subsubsection{Shared knowledge of code(s)}

Akpos jokes are constructed in Nigerian English. It is taken for granted that the writer(s) of the jokes and the readers are competent in Nigerian English usage. Taiwo (2010) describes English as the predominant language of Nigerian digital written communication. Written communication in the Nigerian online spheres is usually coloured with language mixing. Nigerian internet users colour their expressions with switches involving one of the major languages and Nigerian pidgin (NP). Competence in Nigerian English usage includes knowledge of Nigerian English expressions and slang (e.g. Oga and Madam in Example 1), 
NP, and the ability to code switch between English and NP and/or any of the native languages. Code alternations, especially those which involve Nigerian languages, depend on the languages spoken by the discourse participants, the tenor and subject of the interaction.

The language and style of Akpos joke texts reflect the Nigerian use of English. They also reflect the identity of the writers and recipients of the texts. The English language constructions and the use of language mixing in the jokes mirror the readers and writers as Nigerians. English as the language of the jokes is also a reflection of the linguistic situation of Nigeria. The country has over 400 languages. The English language functions as the country's lingua franca and national language. It is the language of intercultural communication in the country. The choice of English is meant to attract a wide readership across the country's ethno-linguistic groups. The joke texts are brought closer to the target audience through the use of popular Nigerian English expressions and language mixing; for instance, in Example 1 above, see Akpos' question to his Oga in NP.

Another aspect of the code used in conveying Akpos jokes is the use of the linguistic features of computer mediated communication such as the electronic paralanguage including initialisms, logograms, and repetitions of letters and punctuation marks. Instances of this in Example 1 include the repetition of the last letter of the word Oga to indicate length, loudness, and emphasis, while the repetition of exclamation mark is used to indicate emphasis. Example 2 further illustrates aspects of the shared knowledge of codes in Akpos jokes:

\section{Example 2}

Background: Akpos' sister, Bimbo, was about to commit suicide by hanging herself Akpos: Ah ah, Bimbo y d rope?

Bimbo: I wan hang myself jor! [I just want to hang myself]

Akpos: Why all the makeups then?

Bimbo: Are you mad, don't you know my face will b in d papers tomorrow?

In Example 2, code switching is adopted in presenting the first utterance of Bimbo. Also there is the use of computer mediated communication (CMC) induced abbreviations like $y$ (why), $d$ (the) and $b$ (be).

\subsubsection{Shared knowledge of culture, situations, and events in Nigeria}

In his definition of a joke, Richie (2004) posits that jokes are peculiar to the culture of its users. Culture comes into play as it provides the circumstances in which joking is appropriate. Internet communication in Nigeria brings about an emerging cultural trend which draws from the indigenous and popular cultures in the country. Joking in online spheres in Nigeria draws cultural presuppositions from the country's indigenous cultures and emerging national jokelore. ${ }^{3}$ Also, there are inputs from social and political happenings and events in Nigeria in Nigerian online joking.

In Akpos jokes, the writers assume a common knowledge of socio-cultural beliefs in Nigeria. These assumptions may be ethnic, religious, or even politically motivated. In some of the jokes, there are references to social events in the country and popular individuals such as politicians, tele-evangelists, actors, and musicians. Apart from the humorous stereotypes attached to the character of Akpos, several other stereotypes derived from Nigerian cultures are also used in the jokes:

Example 3

Judge: Do you want to live with your mother? 


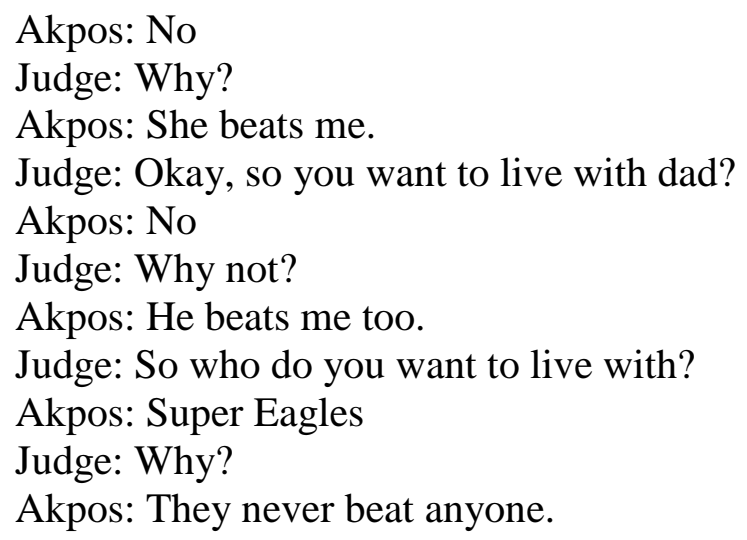

Example 4

Teacher: Why did Zain change to Airtel?

Akpos: Becos Yoruba people kept calling it 'Sane'.

Example 3 mirrors the joke writer's knowledge of social events and individuals in the country. The joke was targeted at the Super Eagles, the country's senior national football team. The team dropped out of the qualifying series of the Confederation of African Football (CAF) Cup in 2015. The joke is meant to connote that the Super Eagles did not earn the ticket for the CAF Cup because they did not "beat" the teams in their qualifying group. Thus, Akpos would rather stay with the team because they would not "beat" him since they were unable to "beat" the teams in their qualifying series.

The word beat has been deliberately chosen by the joke writer so as to enable a switch from one script to another. In the first use of the word, it conjures the script of parental beating which is meant to discipline an erring child. Closely connected to this script is the abuse of corporal punishment by parents who are too strict with their children. In the last use of beat, the word triggers another script involving the poor performance of the country's national football team. Corporal punishment is a common parenting technique in several cultures in Nigeria. It is adopted in several homes and educational institutions like the primary and secondary schools. However, there are parents who kick against corporal punishment. Such parents opine that it inflicts pain on children and it negatively reinforces them. Thus, the joke writer draws on the cultural beliefs of Nigerians about corporal punishment and the poor performance of the Super Eagles. Example 3 underscores the debates about parental beating by activating scripts connected to it and then switching scripts to the poor performance of the national football team.

In Example 4, the joke writer made use of the collective knowledge of Nigerian English usage, especially, the inability of Yoruba speakers of English to overcome their first language interference in their spoken English. The sound /z/ is absent in Yoruba phonology, therefore, in their spoken English, Yoruba speakers use the closest sound to the voiced alveolar fricative, which is /s/. Thus, for the Yoruba speakers of English, Zain, which should be articulated as /zein/, is pronounced as /sein/. Zain is the name of a telecommunication company in the country which was later acquired by Airtel, another telecommunication company. With Airtel's buyout of Zain, the company name was changed to Airtel. The joke thus draws on the background knowledge of how an ethnic group in Nigerian speaks English. It also stereotypes the members of the ethnic group as people with poor spoken English. Moreover, it mirrors the events in the country's telecommunication industry. There is also the use of CMC induced abbreviation: the word because was spelt bcos in the joke. This abbreviation reflects the medium through which the joke is presented to the recipients: 
Facebook, a social networking site that permits the use of electronic paralanguage (Knight 2008).

\subsection{Conversational features of Akpos jokes}

Studies on CMC have shown that interactions carried out via the digital media reflect properties of spoken speech such as conversational initiation-response timing (Crystal 2006, 2011; Knight 2008). Since CMC does not have the physical context of face-to-face interaction, several nonverbal cues such as prosody and gestures that could aid in the interpretation of utterances are absent. Interactants in CMC, therefore, resort to textual cues in CMC environments (Herring et al. 2013). Yus (2011: 118) describes these textual cues as having "a high oral quality that is coded by means of repetitions of letters, capitalisation and creative use of punctuation marks, as well as the use of emoticons". These textual cues are used to convey attitude and intentions (Knight 2008; Crystal 2011; Yus 2011). In addition, as shown by Knight (2008) and Vandergriff (2010), they are used in expressing humour in the online sphere. As seen in Examples 1, 2, and 4, Akpos jokes writers do make use of these features. In Example 1, the repetition of letters and punctuation marks is adopted (e.g. Ogaaaaaaa!!!), while in 2 and 5 nonstandard spellings are used (e.g. becos and $b$ ).

Akpos jokes are written texts which are propagated through word based CMC. They are circulated through online conversations. The online channel used for Akpos jokes can be described as asynchronous in that participants' contributions are stored in the platform and can be viewed at a later time by anyone. For instance, Akpos joke writers could post a joke on the Facebook page, while the readers may post their comments at a later time. The joke writers may, in turn, go back to the page to view the reactions to the jokes. These jokes are usually in the form of running texts, as seen in the examples above. However, we cannot rule out instances in which texts are inscribed on pictures or when they are constructed in cartoon formats. The readers can catch up with the jokes posted on the page, while the writers can view the reactions to their jokes at any time. The joke readers do not have to be online while the jokes are being published on the page. Likewise, the joke writers do not have to be online while the readers are posting their reactions to the jokes. Because of the CMC medium, feedback from recipients could be delayed or immediate. Following boyd (2007), Akpos jokes are characterised by persistence (the jokes can be stored indefinitely), replicability (the jokes can be copied and pasted from one area to another), and invisible recipients (any person can access the jokes).

An important conversational feature of Akpos jokes is the use of opening and closing markers. These markers serve as contextualisation cues which signal the start of the jokes and their closing. In between the opening and closing markers is the actual presentation of the joke. Unlike verbal and unmediated conversational joking where response stage follows closely after joke telling (Attardo 1994), Akpos jokes have closing phrases which trigger the responses from the readers. Example 5 illustrates the use of these contextualisation cues.

\section{Example 5}

Three men in the desert

Akpos, John and Rukewe were stranded in the Sahara desert, when they saw a bottle of wine. They were so happy because they hadn't taken a drink in days. They decided to share the drink equally among themselves. John would take the top one-third, Rukewe would take the second, and Akpos would take the last. Since it was evening, they decided to keep it till the next morning, before drinking. Then they made themselves 
swear not to steal the wine. The next morning, the bottle of wine was empty. After cross examination, Akpos admitted he drank it.

They asked him why and he said, "I woke up in the middle of the night, and was thirsty. But since my portion was at the bottom of the bottle, I had to drink through yours to get to it"

Please is Akpos at fault?

Opening phrase: "Three men in the desert"

The joke: "Akpos, John and Rukewe were stranded... I had to drink through yours to get to it"

Closing Phrase: "Please is Akpos at fault?"

The writers of the joke use the opening markers to suggest what the joke is about while the closing markers are used to align responses towards a particular direction such as appreciating the joke and/or appraising the character of Akpos. Pragmatically, the opening markers activate the needed background information for understanding the jokes, while the closing markers are used to invite the readers to give their responses. In verbal conversational joking, the telling of the joke typically ends with the presentation of the punchline, but in Akpos jokes, the telling of the joke ends with the closing markers. Some other examples of opening markers are "Akpos at the cinema" (for a joke where Akpos went to the cinema), "Akpos final exam" (for a joke where Akpos was to write his final examination in a police training school), and "Akpos the taxi driver" (for a joke where Akpos was a taxi driver). Examples of closing markers are "One word for Akpos", "How many LIKEs for Akpos" and "LIKE if funny".

There is also the use of implicatures in narratives. A conversational implicature is deliberately weaved into the jokes, with the major character, Akpos, flouting the conversational maxims in order to create mirth in the readers. The flouting of Gricean maxims as the basis of humour is made possible because the jokes are usually composed and structured as conversations between Akpos and other characters, usually not more than three in number. Grice's cooperative principles have been used to account for humour in conversations. According to Attardo (1994: 271-272), "a large number of jokes involve violations of one or more of Grice's maxims [...] the claim that jokes could be viewed in terms of violations of maxims dates back to Grice himself, who considers irony as an example of implicature". Instances where implicature is used as the basis of humour in the jokes are seen in Examples 6 and 7:

Example 6

Akpos was lying unconscious in a hospital bed. After a week he finally regained consciousness. The doctor was immediately summoned.

DOCTOR: Your recovery was a miracle.

AKPOS: Thank God! That means I don't have to pay you.

Example 7

Teacher: What is the chemical formula for water?

Akpos: H I J K L M N O.

Teacher: What are you talking about?

Akpos: Yesterday, you said it's $\mathrm{H}$ to $\mathrm{O}$ 
In Example 6, Akpos understands that after being treated by a medical doctor, he would have to pay for the services rendered in the hospital. So, when he was told that his recovery from his unconscious state was a miracle, he decided to flout the maxim of relevance by talking about the payment of bills, rather than making his contribution to be related to the doctor's utterance. Akpos' utterance generates the implicature that he has no money to pay the doctor. It is important to note that in the Nigerian context, it is commonly believed that getting one's heath restored is a function of being healed supernaturally and not a function of the care and treatment one receives from a doctor. It is this background belief that serves as the basis of Akpos utterance.

Similarly, he flouts the maxim of relevance in Example 7 when he recites the alphabet from letter $\mathrm{H}$ to $\mathrm{O}$. This generates the implicature that Akpos does not know the chemical formula for water. The writer of Example 7 manipulates shared knowledge of language. The writer uses Akpos' utterance to pun on the chemical formula for water, which is written as $\mathrm{H}_{2} \mathrm{O}$ and pronounced in Nigerian English as /et tu oh/. For Akpos, the teacher meant the English alphabet letters $\mathrm{H}$ to $\mathrm{O}$ and not the formula $\mathrm{H}_{2} \mathrm{O}$. Besides, in the Nigerian educational context, the chemical formula for water is one of the scientific formulas that students are exposed to at the preceding stage of secondary education; therefore, it is assumed that every student should know the formula.

\section{Responses to Akpos jokes}

In conversational joking, responses to jokes are considered significant in joking exchanges. The response phase indicates a change in the conversational roles of both the joke teller and recipient. The joke teller moves from speakership to recipiency while the joke recipient moves from recipiency to speakership. Attardo (1994) maintains that the response phase in joke telling is the most complex of the three phases of joke telling. He identifies three classes of responses: laughter, delayed laughter, and silence. The response phase seems complex because it may be difficult to pin down recipients' responses to specific meanings; for instance, silence may mean that the recipients did not understand the joke, or that they understand the joke but did not want to publicly indicate that they find the joke funny, or maybe they did not find it funny at all.

Joke writers in online humour have to make "use of emergent instruments of expression (e.g. emoticons abbreviations, graphics) that transform the online space into a dynamic stage for creative communication and language play" (Marone 2015: 63). Similarly, the recipients of online humour have to use the same means to express their responses. Joke recipients in online humour have to type their responses. In what follows, the ways the readers of Akpos jokes responded to the jokes published on Akpos the comedian are analysed. I begin the analysis by illustrating the forms of the responses, and then, I move on to exploring the significance of the responses.

\subsection{Forms of responses}

By forms of response, I mean the specific semiotic means by which the recipients express their responses to the jokes. These involve language, pictures, or a combination of the two. Language could entail the use of CMC motivated expressions such as computer paralanguage, emoticons, misspelling, capitalisation, or unconventional punctuation. The forms of responses are not peculiar to the joking interactions as they could be used in other online interactions. However, they are significant as they indicate how CMC influences joking responses in the Nigerian context. Response forms are also influenced by the shared 
knowledge of code which is peculiar to the CMC environment in the Nigerian ESL context. The following are the types of responses found in Akpos jokes.

\subsubsection{Minimal response}

I use the term minimal response to refer to those responses in which recipients indicate, without commenting on the jokes, that they appreciate a joke. Facebook allows participants to express their reactions to posts by commenting on the post, sharing the post and liking the post. Minimal response refers to the 'likes' on the jokes. I consider the act of liking each joke as a form of response, albeit minimal, to the joke and the joke teller. Liking a comment or post is a feedback mechanism in Facebook interactions. Barton \& Lee (2013: 89) discuss the pragmatic significance of "liking" posts on Facebook. They initially observe that liking a post is a means of evaluation. They opine that liking means indicating that a post has been read, expressing positive stance while not commenting, expressing interest in a post or its content, showing support for the content poster, agreeing/aligning with the stance of the status poster, and, answering yes to a question raised in the post. For the present purpose, liking the jokes indicates that the jokes have been read and enjoyed and have been found humorous. It indicates that the readers share the same presuppositions about the character of Akpos and the codes that can be used in CMC environment in the Nigerian ESL context. Contextually, liking gives a positive evaluation of the jokes and indicates that the intention of the writer of the humorous post has been fulfilled. A large number of the jokes received several likes, ranging from eighty to above two hundred. The number of likes indicates the popularity of the jokes amongst the followers of the Akpos jokes page.

Next is sharing the joke on readers' Facebook pages. Sharing a post on Facebook implies that a Facebook user is re-posting the joke on his/her page. In conversational joking, participants usually repeat jokes which they find pleasurable and which they want others, friends and acquaintances, to enjoy. Likewise, a recipient of Akpos joke who chooses to share the joke on his/her own page indicates that s/he finds the joke pleasurable and wants others who have not seen the joke to enjoy it, too.

\subsubsection{Adoption of language play}

Humour is seen as a form of language play, although language play may not necessarily be humorous (Vandergriff 2010). Humour may entail language play because humorous language involves deliberate distortion of language and subversion of social structures (Mintz 1985; Vandergriff 2010). According to Cook (2000), language play includes a range of normally dissociated activities which entails disconnection from reality, disruption and subversion of social structures, and introduction of random elements. Vandergrift (2010) identifies two types of spontaneous humorous play in CMC: form-based play, which is playing with language, and pragmatic play, which is playing within language. Form-based language play is defined as the manipulation of linguistic form. It is motivated by linguistic creativity and the absence of nonverbal cues in CMC environments. On the other hand, pragmatic play does not manipulate linguistic form and meaning, since it "uses language in unexpected ways at the level of understanding and does not reveal itself in the linguistic form" (Vandergriff 2010: 238).

Primarily, form-based play includes instances of computer paralanguage; few examples found in the data are 4ny (funny), Nyc 1 (nice one), and lol (laugh out loud). Pragmatic play, on the other hand, may include instances of irony and a participant playing with his/her identity. In instances where readers adopt irony, they pragmatically expand the success of the joke in order to present their response. The most common pragmatic play involves the manipulation of identity. A number of readers manipulated their identity by adding to their 
names the names of popular public figures such as hip hop artists. For instance, one of the readers has the name of $D M X$ added to his while another adopted $J a$ Rule $e^{4}$. Playing with identity is made possible because the participants usually do not know each other personally. By choosing the names of hip hop artists as part of their names in the CMC environment, these participants establish an identity which mirrors what the actual bearers of the names are known for, and with which the other participants view them. Another instance of manipulation of identity which is found is the use of titles which indicates the religion of the bearer: for instance, Alhaji, a title adopted by a Muslim man who has made pilgrimage to Mecca, was adopted by a recipient who commented on the joke. By adopting Alhaji, the participant, who may not be a Muslim, indicates affiliation with Islam.

In the responses to Akpos jokes, the recipients adopt different forms of computer paralanguage which include initialisms, abbreviations, nonstandard spellings, and grapheme substitutions; these are exemplified in Table 1. The implication of language play is that the readers are expanding the success of humour. By adopting the playful mode, the readers' responses, too, can function as humorous stimuli for other readers. Vandergriff \& Fuchs (2012) attest that producing more humour is a prominent method of humour support in online joking.

Table 1. Types of form-based play

\begin{tabular}{|c|c|c|}
\hline $\begin{array}{l}\text { Type of computer } \\
\text { paralanguage }\end{array}$ & Examples from responses & Standard form/meaning \\
\hline Clipping & $\begin{array}{l}\text { See tmrw; vry true; wat's funny? Tell } \\
\text { me; Daz funny; wot funny abt dis; u a } \\
\text { nw mad; Nyc prayer; Gud; kul }\end{array}$ & $\begin{array}{l}\text { See tomorrow; very true; } \\
\text { what's funny? Tell me; } \\
\text { That's funny; What (is) } \\
\text { funny about this; you are } \\
\text { now mad; Nice prayer; } \\
\text { Good; Cool }\end{array}$ \\
\hline $\begin{array}{l}\text { Punctuation } \\
\text { (repetition of } \\
\text { punctuation marks and } \\
\text { capitalisation) }\end{array}$ & $\begin{array}{l}\text { It is finish!!!!!!!!; I knew it.......lolz I } \\
\text { love this }\end{array}$ & $\begin{array}{l}\text { It is finished!; I knew } \\
\text { it...LOL I love this. }\end{array}$ \\
\hline $\begin{array}{l}\text { Initialisms and } \\
\text { abbreviations }\end{array}$ & lwkmd; Lol ${ }^{5}$; OMG; Lmao; lwkm & $\begin{array}{l}\text { Laf wan kill me die [I } \\
\text { almost died laughing]; } \\
\text { laugh out loud; Oh my } \\
\text { God; Laugh my ass out; } \\
\text { laf wan kill me[I almost } \\
\text { died laughing] }\end{array}$ \\
\hline Logograms & $\begin{array}{l}\text { 4ny; 9ice, Na tree u g0 s00n dey climb } \\
\text { yeye man (the focus here is on g0 } \\
\text { s00n, which is a combination of } \\
\text { numerals and letters) }\end{array}$ & $\begin{array}{l}\text { Funny; nice; na tree you } \\
\text { go soon dey climb, funny } \\
\text { man [Translation: You } \\
\text { will soon be climbing } \\
\text { trees, you clown!] }\end{array}$ \\
\hline $\begin{array}{l}\text { Combination of } \\
\text { paralanguage }\end{array}$ & $\begin{array}{l}\text { D question is } 2 \text { much } 4 \mathrm{~d} \text { girl if } \mathrm{u} \text { ask } \\
\mathrm{d} \text { teacher; Gud } 1 \text {; lwkm o hahahaha ct } \\
\text { stp laughing; who ill hlp Akpos } 2 \text { say } \\
\text { amen! }\end{array}$ & $\begin{array}{l}\text { The question is too much } \\
\text { for the girl if you ask the } \\
\text { teacher; good one; laugh } \\
\text { wan kill me oh, hahahaha } \\
\text { can't stop laughing; who } \\
\text { will help Akpos to say } \\
\text { amen! [Translation: who }\end{array}$ \\
\hline
\end{tabular}




\begin{tabular}{|l|l|l|}
\hline & & $\begin{array}{l}\text { will say amen to Akpos } \\
\text { prayer!] }\end{array}$ \\
\hline
\end{tabular}

\subsubsection{Adoption of language mixing}

Language mixing is the use of more than one linguistic system in discourse. It entails the use of code mixing and code alternation. Language mixing in the readers' responses is better understood if the linguistic situation of Nigeria is considered.

Nigeria is a linguistically diverse country with over four hundred native languages and dialects, and three exoglossic languages, English, French, and Arabic. The ethnologue report of Summer Institute of Linguistics in 2009 puts the number of indigenous languages in Nigeria at 514 (Lewis 2009). There is also Nigerian Pidgin (NP), a contact language which was initially spoken in the costal regions of the country, but now functions as a lingua franca among the youths and in several southern cities in the country. NP is also the language used by the government for advertisements (Taiwo 2010).

The recipients of the jokes use primarily two languages, English and NP, to express their reactions to the jokes. In some instances, readers switch from English to NP and vice versa. Some recipients also adopt linguistic expressions from the major Nigerian languages in their responses which were rendered in English or NP.

Responses in English:

I will sing praises on his cheeks

I will pay money to buy new one

Responses in NP:

hahahahahaha you don buy market

[Translation: You are in debts]

Na true na

[Translation: It is indeed true]

Responses involving code alternation:

Yoruba talk say oju loro wa which mean na face talk dey ${ }^{6}$

[Translation: A Yoruba proverb says conversations demand full attention, which means that people must pay attention while conversing]

Thief!!! OLE!!!! BARAWO!!!!?

The popular choice of using English and NP is not unconnected with the fact that they cut across ethnic nationalities in Nigeria. Thus, the recipients, in using these languages, want their reactions to be accessible to people across various ethnic nationalities. English is primarily the language of CMC in Nigeria, while interactants in Nigerian CMC only adopt NP when the tenor and the subject of their discourse are not formal (Taiwo 2010).

Instances of language mixing are markers of the participants' ethnic and national identities. They use an indigenous language, e.g. Yoruba, Hausa, or Igbo, to depict their Nigerianess and to affiliate with the respective ethnic group. On the dynamics of language mixing in Nigerian CMC, Taiwo (2010: 183-184) asserts that

[o]ne major feature of language use in digital communication by Nigerians is language mixing. The heterogeneous sociolinguistic landscape of the country encourages this practice. English is the predominant language of digital written communication in the country [...]. Oftentimes, users flavour their communication with switches from English to any of the three major languages and 
NP. Nigerians who participate in online communication are well educated people, who are capable of sustaining meaningful discourse in English. Their code-switching is therefore a conscious choice geared towards reflecting their desire for identity with some particular language varieties.

\subsubsection{Adoption of multiple semiotic modes}

Another feature realised in the readers' responses is the use of both pictures and language. This is what I termed multiple semiotic modes. Few readers adopt pictures together with stylish typeface in expressing their reactions to the jokes, what could technically be regarded as memes. The term meme was introduced by Dawkins (1976) to refer to cultural units which are spread from person to person. Since these memes are transmitted via the internet, they are internet memes. While being circulated online, internet memes are reshaped and transformed by their users; memes are also adopted for creating a shared cultural experience (Shifman 2013). Memes are effective communication tools because of the visual rhetorics that are employed in creating them. Milner (2013) suggests that the predominant purpose of visual rhetorics in memes is satirical humour.

In the memes used as responses to Akpos jokes, two semiotic modes, picture and language, are combined to convey the recipient's negative or disapproving reaction to the joke. Figures 1 and 2 illustrate memes used as responses to Akpos jokes:

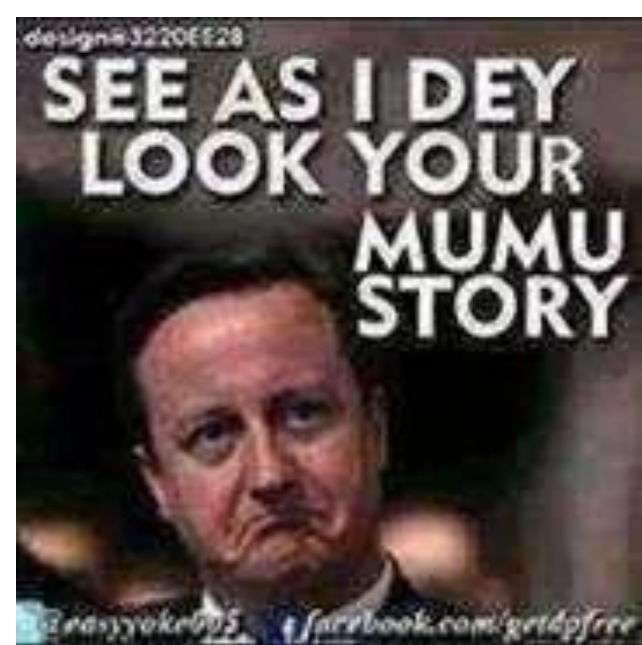

Figure 1: D. Cameron meme

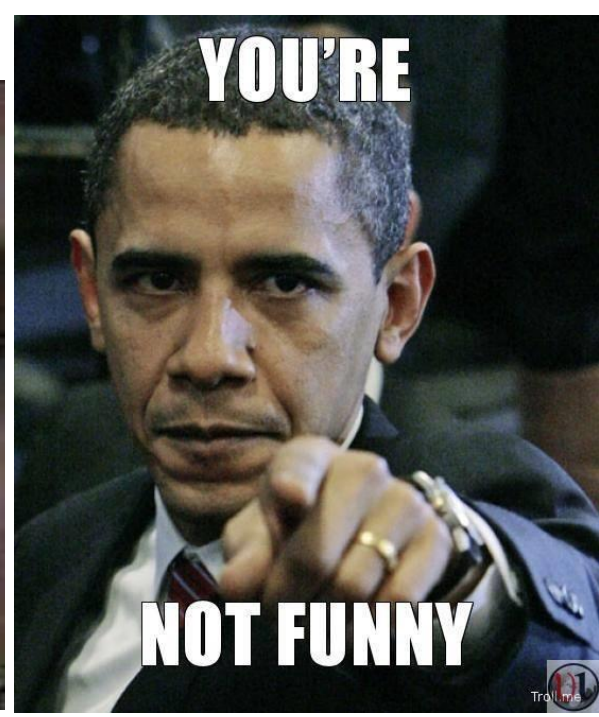

Figure 2: B. Obama meme

These figures illustrate the use of both language and picture. The pictures used are images of two world figures, the former British Prime minister David Cameron (DC) in Figure 1, and the US President Barrack Obama (BO) in Figure 2. The pictures are iconic signs for DC and BO. The import of these pictures is in what they symbolise and the intention of the users. In Figure 1, DC wears a look which signifies that he is disinterested, unimpressed, and displeased. His facial expression connotes the user's reaction to the joke. In semiotic terms, it is indexical of the user's attitude. A downcast facial expression signifies that the user is displeased with and unimpressed by the joke. Likewise, Figure 2 shows BO pointing the index finger, an abstract pointing and a form of deictic gesture (see McNeil 2006). The deictic gesture points to the writer of the joke.

The use of the images of DC and BO has pragmatic and discursive significances. The images of these individuals evoke political power and authority. What the users did is to take the images as signifiers for power and authority in their primary domain of international 
politics, and then recontextualise them in a secondary domain - the domain of the joke, as signifiers for the attitude towards and assessment of the joke. In discursive terms, the pictures involve the processes of entextualisation and resemiotisation, both of which entail the processes of decontextualisation and recontextualisation (Blommaert 2005; van Leeuwen 2005; Leppänen et al. 2014). The pictures are made to cross the discourse and social boundary from politics to humour, as well as a geographic boundary - from the UK and the USA to Nigeria. Taking the pictures from their traditional domains and placing them in Nigerian cultural domain has implications for the performance of humour. The recipients who adopted the images of DC and BO evoke political power and authority, as a pointer to their conversational authority to evaluate the humorousness of the jokes. These responses show that the joke recipient is endowed with conversational authority to determine the felicity of the joke act performed by the Akpos joke writers. Their use also shows that boundaries, especially in the online sphere, are fluid as interactants can switch from one domain to another.

Apart from the iconic signs in the Figures, the recipients also use language to express their reactions to the joke. Specifically, Figure 1 contains a number of inscriptions, two of which have nothing to do with the joke. ${ }^{8}$ Our concern here is the utterance written in NP, See as I dey look your mumu story [Translation: Look at the way I am looking at your stupid story], which implies that the recipient did not find the joke humorous. On the Barack Obama picture, You're not funny is inscribed using the English language. These expressions are used to substantiate the meanings that are deciphered from the images. In Figure 1, the recipient adopted a label, тити, which is an abusive term, to evaluate the joke. Мити implies that the joke teller's joke is infelicitous. In Figure 2, too, the recipient openly condemned the joke teller with the response: you're not funny.

\subsection{Functions of responses}

\subsubsection{Indicating affiliation}

Some reactions indicate affiliation with the intention of the joke writers to generate humorous reactions from the readers. This set of responses expresses that the readers found the jokes humorous. Examples are LWKMD (laugh wan kill me die), lol (laugh out loud), and 4ny (funny). Such reactions imply that the readers cooperate with the joke writers. The pragmatic import of affiliative responses is that the readers share the same presuppositions about the jokes with the joke teller. Indicating affiliation is thus a marker of in-group identity between the joke teller and recipients.

\subsubsection{Indicating failed humour}

When a joke puzzles, irritates or is repulsive to its recipients, it becomes an instance of failed humour (Laineste 2013). Such a joke is often met with anger or critical remark. Some of the responses to the jokes indicate failed humour. Such responses also mark disaffiliation from the jokes. As evaluative remarks, this group of responses criticises the joke and/or the joke writer. Examples of responses in this group are What's funny, This is not a joke, This guy joke don finish tey tey [This person no longer has jokes to tell], I'm out of here!, It is not funny, Too dry and What's funny? Tell me. An implication of such responses is that the readers do not share the same presuppositions with the joke writers about the joke text. 


\subsubsection{Changing the topic}

The last class of responses is made up of reactions which contain propositions that are not in any way related to the topic of the jokes or to the intention of the joke writers to initiate humour. This class of reactions show that the readers changed the "topic of the discourse" (Brown \& Yule 1983). Responses that change the topic of the discourse break the sequence of joke performance in CMC and are not coherent with the joke text.

Some of the responses that fall under this category are comments that advertise a product, e.g., a newly realised song by an upcoming artist or another social media page such as a blog or another Facebook page. Changing the topic in an online joking situation is an instance of pragmatic play since it involves a manipulation of joking situation beliefs and participants' presuppositions underlying the joking exchange. To change the topic, a joke recipient will have to discard the joke teller's presuppositions and establish other presuppositions for his/her own topic. Like the joke teller, the recipient who changes the topic will have to assume that the topic to be introduced will be relevant to the joke teller and other individuals who would read the disconnected contribution. Given the cooperative maxims (Grice 1975), however, the inference that will be derived is that the participant whose contribution changes the topic did not join the joke exchange for the purpose of enjoying humour.

\section{Discussion}

Akpos jokes and the responses they generate have the following implications:

1. Akpos joke writers and the readers are members of the same community. Although some responses may indicate failed humour and some may change the topic, all the responses, just like the jokes, are expressed with primarily two codes, English and NP. This shows that the participants in Akpos jokes share more or less the same knowledge of language and have similar experiences in linguistic performance in online interactions. Apart from using the same language code, the participants also adopt similar linguistic patterns which are induced by the $\mathrm{CMC}$ environment. The CMC induced forms further underscore that they have similar experiences in terms of linguistic communication in internet mediated interactions.

2. In the public joking sphere, recipients may use their responses to contest the humorousness of the joke. In a stream of responses, the readers argue about the funniness of the joke. Responses arguing for the humorousness of a joke which has been earlier described as non-humorous could be described as contestive responses. Contestive responses come into play when a participant argues that a joke is humorous after another participant has indicated the opposite. Contestive responses reject earlier disaffiliative responses and then project a positive evaluation of a joke.

As a reaction to one of the jokes, a reader posted the comment It not funny too dry to indicate his disaffiliation to the joke and its failure. However, another reader contested that the joke in question was funny and argued that the recipient did not find the joke funny because he has been cut off from what's happening in Nigeria's political scene. The comment of the recipient who argued that the joke is funny is presented below:

@ raphael if u r current then u will know that this story is wet and not dry, a member of house of rep had to climb the gate for certain reason so akpos is qualified he has climbed gates that is higher than that. Lols ${ }^{9}$ 
[Translation: @ Raphael, if you are conversant with political events in the country, then you will know that the joke is wet (funny) and not dry; a member of the House of Assembly had to climb the gate for certain reason. So Akpos is qualified since he has climbed gates that are higher than that. Lols]

The joke which generated these responses was targeted at the Speaker of Nigeria's Federal lower legislative arm of government, namely the House of Representatives. The Speaker had climbed the gate of the National House of Assembly in order to gain access to the lower chamber when he was locked out by security forces. It was the Speaker's act of climbing the gate that was satirised by the joke.

With this contestive response, the recipient argues that the joke is actually funny. The recipient argues that Raphael, who had given the disaffiliative comment it not funny, too dry, has not taken into cognisance the satirical import of the joke in the Nigerian context. Raphael failed to relate the joke to the political events in Nigeria. In the contestive response, the recipient made it explicit that the joke was about an action in Nigeria's political scene and that the reader that indicated failed humour did not take into cognisance the presuppositions of the joke writer. The recipient uses the contestive response to implicitly strengthen the communal bond between herself and the joke writer.

Contending the humorousness of a joke underscores that funniness is not an inherent property of jokes. Finding a joke funny is dependent on a number of factors. According to Attardo (2009), experiencing humour results from perceiving a stimulus for humour, and finding the stimulus funny is dependent on external factors such as the state of mind of the recipient and the existence of relevant background knowledge to process the joke text. Instances where contestive responses exist in the stream of comments on Akpos jokes reflect that humour is not an inherent property of text.

\section{Conclusion}

In this article, readers' responses to Akpos jokes have been described and analysed. This paper begins with a description of Akpos jokes. Although the response stage is a significant aspect of the joking exchange, responses to jokes, especially those found in ESL context, have not been given adequate attention within humour research. This study is a modest attempt to spur humour researchers to examine joke recipients' reactions together with jokes and their functions. The analysis begins with identifying the presuppositions underlying the jokes and the conversational features of the jokes. Because the jokes are instances of internet mediated humour, the readers exploit the affordances of the online environment to react to the jokes. Through the use of language mixing, the responses portray the ESL context in which the jokes are situated. Also, the responses show how reactions to a joke may be used to contest the humorousness of the joke.

Finally, there are other aspects of Akpos jokes that can be investigated. For instance, Akpos jokes found in blogs can be compared with those found on Facebook pages. It has been observed above that the jokes are characterised by replicability, hence a study may investigate similarities and differences as the jokes are reproduced in different online forums.

\section{Notes}

1 Nigeria has over 400 ethnolinguistic groups which are classified into two broad categories: major and minor. Only three groups make the major class, i.e. Yoruba, Hausa, and 
Igbo, while the other ethnolinguistic groups are seen as minor. I have argued that the character of Akpos represents the people of the Niger-Delta region of Nigeria. This region is home to some ethnic minorities such as Ijaw, Itsekiri, and Urhobo. The classification of these groups as minority ones is perceived as denigrating by the indigenes.

${ }^{2} \mathrm{O}$ is a discourse marker in Yoruba language which places emphasis on the meaning conveyed in the utterance where it is used.

${ }^{3}$ The term national jokelore is used to refer to relatively new joking practices in Nigeria such as stand-up comedy, which attract participants across ethnolinguistic divides and which are conveyed by the language used for wider communication. It contrasts with joking practices found in the indigenous tribes of the country.

${ }^{4}$ DMX and Ja Rule are award winning American hip hop artists. Around mid-1990s, American hip hop music became popular in Nigeria amongst the youth.

${ }^{5}$ It is important to comment on $\mathrm{Lol}$, which has various realisations in the data (lols and $l o l x)$. Whenever $-s,-z$ or $-x$ is placed after $l o l$, it is an indication of intensified laughter. The letters $s, z$, or $x$ on $l o l$ are taken in this context as indicators of plural and they relate to the use of English as a second language in Nigeria. In CMC, Nigerians take $s, z$ or $x$ as plural markers and this stems from the plural markers in Standard English.

${ }^{6}$ In translating Yoruba proverb Oju loro $w a$ into NP, the recipient has played on the Yoruba word oju which could be translated as "face", "eye", or "surface", depending on the context. This is an instance of both pragmatic play and language play which have been described earlier.

${ }^{7}$ Ole is the Yoruba word for "thief", while barawo is the Hausa word for "thief".

8 The inscriptions on the top and bottom of the picture are the social media address (his/her blackberry pin, twitter handle and Facebook page) of the user of the picture.

9 The joke in question is meant to lampoon the Nigerian legislators who occupy the lower house of the Federal Legislative arm of government. In November 2014, some members of the lower legislative house, including the Speaker, were locked out of the National Assembly by the Nigerian police force. The legislators had to climb over the gate to re-enter the chambers.

\section{References}

Adetunji, A. (2013). 'The interactional context of humour in Nigerian stand-up comedy'. Pragmatics 23 (1), pp. 1-22.

Adeleke, D. (2007). 'Parody of the Shakespearean fool tradition in an African society'. Journal of Social Sciences 15(1), pp. 35-42.

Akpos Jokes. [Online] http://www.akposjokes.com. [Accessed 5 January 2015.]

Attardo, S. (1994). Linguistic Theories of Humour. New York: Mouton de Gruyter.

Attardo, S. (2009). 'Salience of incongruities in humorous texts and their resolution', in Chrzanowska-Kluczewska, E. \& Szpila, G. (eds.), In Search of (Non)Sense, Newcastleupon-Tyne: Cambridge Scholars Publishing, pp. 164-179.

Ayakoroma, B. F. (2013). 'The rise of stand-up comedy genre in Nigeria: From nothing to something in artistic entertainment'. Paper presented at the Society of Nigeria Theatre Artists Annual Conference, Benue State University, Makurdi, 4-8 June.

Barton, D. \& Lee, C. (2013). Language Online: Investigating Digital Texts and Practices. London: Routledge.

Blommaert, J. (2005) Discourse: A Critical Introduction. Cambridge: Cambridge University Press. 
boyd, D. (2007). 'Social network sites: Public, private, or what?'. The Knowledge Tree 13, (May). [Online] http://www.danah.org/papers/KnowledgeTree.pdf. [Accessed 5 January 2017.]

Brown, G. \& Yule, G. (1983). Discourse Analysis. Cambridge: Cambridge University Press. Cook, G. (2000). Language Play, Language Learning. New York: Oxford University Press.

Crystal, D. (2006). Language and the Internet. Cambridge: Cambridge University Press.

Crystal, D. (2011). Internet Linguistics. London: Routledge.

Davies, C. (1990). Ethnic Humour around the World: A Comparative Analysis. Bloomington: Indiana University Press.

Dawkins, R. (1976). The Selfish Gene. Oxford: Oxford University Press.

Delogu, F. (2009). 'Presuppositions', in Verschueren, J. and Östman, J.O. (eds.), Key Notions for Pragmatics, Amsterdam/ Philadelphia: John Benjamins, pp. 195-207.

Dynel, M. (2009). 'Beyond a joke: Types of conversational humour'. Language and Linguistics Compass 3 (5), pp. 1284-1299.

Ermida, I. (2009). 'Together or apart: Targeting, offence and group dynamics in humour'. JoLIE 2(2), pp. 93-104.

Gabriel, G. (2012, August 26). Ali Baba: I had so many scattered dreams before comedy fell into place. Vanguard Newspapers. [Online] http://www.vanguardngr.com/2012/08/alibabai-had-so-many-scattered-dreams-before-comedy-fell-into-place/. [Accessed 11 August 2013.]

Galiñanes, C.L. (2000). 'Relevance theory, humour, and the narrative structure of humorous novels'. Revista Alicantina de Estudios Ingleses 13, pp. 95-106.

Goriunova, O. (2012). 'New media idiocy'. Convergence: The International Journal of Research into New Media Technologies 19(2), pp. 223-235.

Grice, P. (1975). 'Logic and conversation', in Cole, P. \& Morgan J. L. (eds.), Syntax and Semantics 3: Speech Acts, New York: Academic Press, pp. 41-58.

Herring, S.C., Stein, D. and Virtanen, T. (eds.). (2013). Pragmatics of Computer-Mediated Communication. Berlin/Boston: De Gruyter Mouton.

Holmes, J. \& Marra, M. 2002. 'Humour as a discursive boundary marker in social interactions', in Duszak, A. (ed.), Us and Others: Social Identities across Languages, Discourses and Cultures, Amsterdam/ Philadelphia: John Benjamins, pp. 377-400.

Knight, N. K. (2008). "'Still cool... and american too!": An SFL analysis of deferred bonds in internet messaging humour', in N. Nørgaard (ed.), Systemic Functional Linguistics in Use: Odense Working Papers in Language and Communication 29, pp. 481-502.

Krikmann, V. (2006). 'Contemporary linguistic theories of humour'. Folklore 33, pp. 27-58.

Laineste, L. (2013). 'Funny or aggressive? Failed humour in internet comments'. Folklore 53, pp. 29-46.

Leppänen, S., Kytölä, S., Jousmäki, H., Peuronen, S. \& Westinen, E. (2014) 'Entextualisation and resemiotisation as resources for identification in social media' in Seargeant, P. \& Tagg, C. (eds.), The Language of Social Media: Identity and Community on the Internet, Basingstoke: Palgrave Macmillan, pp. 112-136.

Lewis, M. P. (ed.), (2009). Ethnologue: Languages of the world. Sixth Edition Texas: SIL International.

Marone, V. (2015). 'Online humour as a community-building cushioning glue'. European Journal of Humour Research 3 (1), pp. 61-83.

McNeil, D. (2006). 'Gesture and communication' in Mey, J. L. (ed.), Concise Encyclopaedia of Pragmatics. Oxford: Elsevier, pp. 229-307.

Milner, R.M. (2013). 'Pop polyvocality: Internet memes, public participation, and the Occupy Wall Street Movement'. International Journal of Communication 7, pp. 23572390 . 
Mintz, L. E. (1985). 'Standup comedy as social and cultural mediation'. American Quarterly 37 (1), pp. 71-80.

Norrick, N. R. (2000). Conversational Narrative: Storytelling in Everyday Talk. Amsterdam/Philadelphia: John Benjamins.

Ritchie, G. (2004). The Linguistic Analysis of Jokes. London: Routledge.

Sacks, H. (1974). 'An analysis of the course of a joke's telling', in Bauman, R. \& Sherzer, J. (eds.), Explorations in the Ethnography of Speaking, Cambridge: Cambridge University Press, pp. 337-353.

Shifman, L. (2013). 'Memes in a digital world: Reconciling with a conceptual troublemaker'. Journal of Computer-Mediated Communication 18 (3), pp. 362-377.

Taiwo, R. (2010). 'The dynamics of language mixing in Nigerian Digital communication', in Taiwo, R. (ed.), Handbook of Research on Discourse Behaviour and Digital Communication: Language Structures and Social Interaction, Hershey: IGI Global, pp. 180-190.

van Leeuwen, T. (2005) Introducing Social Semiotics. London: Routledge.

Vandergriff, I. (2010). 'Humour and play in CMC', in Taiwo, R. (ed.), Handbook of Research on Discourse Behaviour and Digital Communication: Language Structures and Social Interaction, Hershey: IGI Global, pp. 235-251.

Vandergriff, I. \& Fuchs, C. (2012). 'Humour support in synchronous computer-mediated classroom discussions. HUMOR: International Journal of Humour Research 25(4), pp. $437-4581$.

Yus, F. (2003). 'Humour and the search for relevance'. Journal of Pragmatics 35, pp 12951331.

Yus F. (2011). Cyberpragmatics: Internet-mediated Communication in Context. Amsterdam/Philadelphia: John Benjamins. 